\title{
BARRIERS AND CONFORMATIONS
}

\author{
William G. FATELEY \\ Department of Chemistry, Kansas State University, \\ Manhattan, Kansas 66506, USA
}

\begin{abstract}
The theoretically calculated barriers for the $\mathrm{OH}$ rotor in parasubstituted phenols are in very good agreement with those found experimentally. Further measurements on a large number of monosubstituted phenols provide sufficient data to allow the prediction of barriers and torsional frequencies in multisubstituted phenols.

Obviously, mesomeric and inductive are linear effects in phenols and this encourages the prediction of other barriers and torsional frequencies in aromatic systems. A new parameter $\Delta \omega_{\tau}$ is introduced to describe the electronic climate about the $\mathrm{C}-\mathrm{O}$ bond better.

Asymmetrical potential functions are investigated for $\mathrm{C}-\mathrm{C}, \mathrm{C}-\mathrm{O}, \mathrm{C}-\mathrm{N}$ and $\mathrm{C}-\mathrm{S}$ single bonds. The influence of different groups, geometric changes during rotation and higher order terms are discussed. Empirical data are given for the effects of different groups on internal rotation.
\end{abstract}

\section{PREFACE}

Certainly this Conference provides a beautiful environment for asking some questions important to conformations in macromolecules:

1. Can barriers to internal rotation be predicted from:

(a) experimentally determined parameters?

(b) theoretical calculation?

2. Can barrier information be successfully applied to macromolecules?

Let us examine these questions in parts. First, the theoretically predicted barriers agree well with experimental results. The experimental results for barriers are found to be useful in predicting $\mathrm{C}-\mathrm{O}$ barriers in phenolic systems, thus demonstrating the transferability of these data. Second, the application of barrier values to large molecules will be discussed in some detail. Interaction, geometric changes and potential surfaces will play important roles in predicting conformations. 


\section{Part I}

Characterization of the Barrier about the Aromatic

Carbon-Oxygen Bond in Phenols

(In collaboration with $\operatorname{Dr}$ G. L. Carlson)

\section{INTRODUCTION†}

Both theory ${ }^{1}$ and experiment ${ }^{2}$ predict that phenol $\left(\mathrm{C}_{6} \mathrm{H}_{5} \mathrm{OH}\right)$ is planar. A planar structure is stabilized by delocalization of the p-type lone pair on oxygen, see Figure 1(a); this is likely to be more effective than the delocalization of the more tightly bound $\mathrm{sp}^{2}$-type lone pair in the orthogonal form, Figure 1 (b). The energy difference represents the barrier to rotation about the $\mathrm{C}-\mathrm{O}$ bond. This barrier is considerably larger than in aliphatic alcohols reflecting. in part, the increased double bond character in the $\mathrm{C}-\mathrm{O}$ bond.

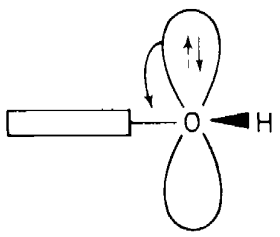

(a)

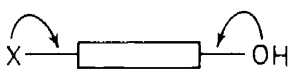

(c)

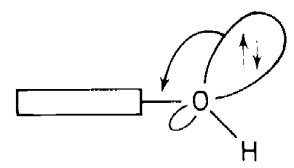

(b)

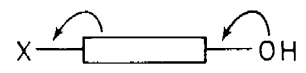

(d)

Figure 1. An end-on view of the benzene ring ( $\square$ ). Part (a) shows the distribution of the p-type lone pair electrons into the bond. Part (b) illustrates the angular dislocation effect. Parts (c) and (d) demonstrate either opposition to, or reinforcement of, delocalization of the oxygen lone pair electrons by the substituent $\mathrm{X}$.

Campagnaro, Hall and Wood $^{3}$ have examined far infra-red spectra of several para-substituted phenols and observed changes in the $\mathrm{OH}$ torsional frequency which correlated with qualitative electronic properties of the substituent $\nrightarrow$. To confirm and extend these ideas, we have carried out $a b$ initio molecular orbital calculations and far infra-red spectroscopic measurements of the torsional barriers in the para-substituted phenols $\mathrm{XC}_{6} \mathrm{H}_{4} \mathrm{OH}$ $\left(\mathrm{X}=\mathrm{OH}, \mathrm{F}, \mathrm{CH}_{3}, \mathrm{H}, \mathrm{CHO}, \mathrm{CN}\right.$ and $\left.\mathrm{NO}_{2}\right) \ddagger$.

Other spectroscopic studies of the effects of para-substituents have been reported for benzaldehydes ${ }^{3}$ and anilines [D. G. Lister and J. K. Tyler, Chem. Commun. 152 (1966); A. Hastie, D. G. Lister, R. L. McNeil and J. K. Tyler. Chem. Commun. 108 (1970)].

$\ddagger$ L. Radom, W. J. Hehre, J. A. Pople, G. L. Carlson and W. G. Fateley, Chem. Commun. 308 (1972). 


\section{BARRIERS AND CONFORMATIONS}

Far infra-red spectra of the phenols in cyclohexane solution $(\sim 0.01 \mathrm{M})$ were obtained by procedures described elsewhere (see ref. 4 and Section II-A). The far infra-red spectra of the analogous phenol-OD compounds were also obtained to confirm the assignments of the torsional frequencies ${ }^{4}$. The theoretical method used is self consistent field molecular orbital theory in the linear combination of atomic orbitals (LCAO) approximation ${ }^{5}$ using the STO-3G basis set $^{6}$ and standard geometries ${ }^{7}$. Orbital and overlap electron populations are calculated using Mulliken's method ${ }^{8}$.

Results are quoted in Table $I$ where the quantities listed have the following meanings. $\Delta V_{2}$ is the change $\uparrow$ in the twofold barrier from the value in phenol, $q_{\pi}(\mathrm{X})$ is the $\pi$ charge on the substituent $\mathrm{X}$ (a positive value indicates that $\mathrm{X}$ is a $\pi$ donor), $\Delta q_{\pi}(\mathrm{OH})$ is the change in $\pi$ charge on $\mathrm{OH}$ relative to the value in phenol, and $\Delta \pi_{\mathrm{C}-\mathrm{o}}$ is the corresponding change in the double bond character of the $\mathrm{C}-\mathrm{O}$ bond as measured by the $\pi$-overlap population. The interaction energy of the substituent $\mathrm{X}$ with the $\mathrm{OH}$ group is measured by the energy

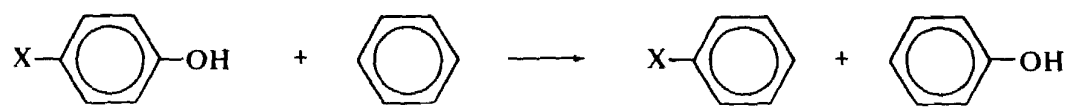

change in the formal reaction(1). If X and $\mathrm{OH}$ do not interact, the energy change in (1) would be zero. Interaction energies are listed for both planar and orthogonal orientations of the $\mathrm{OH}$ group in (1).

There are several interesting points to note from the results in Table 1.

(1) Although the calculated barrier in phenol $\left(5.16 \mathrm{kcal} \mathrm{mol}^{-1}\right)^{1}$ is considerably higher than the experimental value $\left(3.56 \mathrm{kcal} \mathrm{mol}^{-1}\right)$, the changes in barrier with substitution as shown in Table 1 are in quite good agreement.

(2) The barrier is found to decrease when $X$ is a $\pi$-electron donor [positive $q_{\pi}(\mathrm{X})$ charges] and conversely.

(3) These results are easily rationalized in terms of the opposition, Figure 1(c), to, or reinforcement, Figure 1(d), of, delocalization of the oxygen lone pair electrons by the substituent $\mathrm{X}$. Thus, when $\mathrm{X}$ is a $\pi$-donor as in Figure $1(\mathrm{c})$, electron donation by $\mathrm{OH}$ decreases $\left[\Delta q_{\pi}(\mathrm{OH})\right.$ is negative], the double bond character in the $\mathrm{C}-\mathrm{O}$ bond decreases $\left[\Delta \pi_{\mathrm{C}-\mathrm{O}}\right.$ is negative) and the barrier decreases. Conversely, when $X$ is a $\pi$-acceptor as shown in Figure 1(d), electron donation by $\mathrm{OH}$ increases, the double bond character in the $\mathrm{C}-\mathrm{O}$ bond increases and the barrier increases. The theory and experimental evidence thus confirm the conclusions reached by Campagnaro, Hall and Wood ${ }^{3}$.

(4) The calculated values of the interaction energies show that when $X$ is a $\pi$-donor, the interaction between $\mathrm{X}$ and $\mathrm{OH}$ is destabilizing (negative interaction energies) and conversely. This is true in both planar and orthogonal conformations although smaller in the latter. There is an almost linear correlation between the barrier values and the interaction energies in the planar forms.

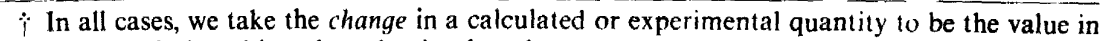
the substituted phenol less the value in phenol. 
Table 1. Calculated and experimental quantities for para-substituted phenols $\left(\mathrm{X}-\mathrm{C}_{6} \mathrm{H}_{4}-\mathrm{OH}\right)$

\begin{tabular}{|c|c|c|c|c|c|c|c|}
\hline \multirow[b]{2}{*}{$\mathrm{X}$} & \multirow{2}{*}{\multicolumn{2}{|c|}{$\Delta V_{2}\left(\mathrm{kcal} \mathrm{mol}^{-1}\right)^{\mathrm{a}}$}} & \multirow[b]{2}{*}{$q_{\pi}(\mathrm{X})^{\mathrm{a}, \mathrm{b}}$} & \multirow[b]{2}{*}{$\Delta q_{\pi}(\mathrm{OH})^{\mathrm{a}, \mathrm{b}}$} & \multirow[b]{2}{*}{$\Delta \pi_{\mathrm{c}-\mathrm{o}} \mathrm{a}^{\mathrm{b}}$} & \multicolumn{2}{|c|}{$\begin{array}{l}\text { Interaction energy } \\
\left(\mathrm{kcal} \mathrm{mol}^{-1}\right)\end{array}$} \\
\hline & & & & & & Planar & Orthogonal \\
\hline $\begin{array}{l}\mathrm{OH} \\
\mathrm{F} \\
\mathrm{CH}_{3} \\
\mathrm{H} \\
\mathrm{CHO} \\
\mathrm{CN} \\
\mathrm{NO}_{2}\end{array}$ & $\begin{array}{c}-0.87 \\
-0.60 \\
-0.32 \\
0 \\
+0.87 \\
+0.70 \\
+0.98\end{array}$ & $\begin{array}{l}-0.95^{\mathrm{b}} \\
-0.53 \\
-0.28 \\
0 \\
+0.47^{\mathrm{b}} \\
+0.66 \\
+1.02\end{array}$ & $\begin{array}{c}+0.096 \\
+0.074 \\
+0.008 \\
0 \\
-0.041 \\
+0.029 \\
-0.039\end{array}$ & $\begin{array}{c}-0.006 \\
-0.002 \\
-0.002 \\
0 \\
+0.006 \\
+0.009 \\
+0.013\end{array}$ & $\begin{array}{c}-0.006 \\
-0.003 \\
-0.002 \\
0 \\
+0.004 \\
+0.006 \\
+0.009\end{array}$ & $\begin{array}{l}-1.4 \\
-0.9 \\
-0.4 \\
0 \\
+0.7 \\
+0.8 \\
+1.3\end{array}$ & $\begin{array}{c}-0.5 \\
-0.4 \\
-0.1 \\
0 \\
+0.2 \\
+0.2 \\
+0.3\end{array}$ \\
\hline
\end{tabular}

- Defined in text " Values quoted lor planar conformations. Even in correlation using Hammett $\sigma$ parameter, the CHO group shows poor correlation. ${ }^{\circ} T$ wofold $\left(V_{2}\right)$ component of barrier calculated via a two-term Fourier expansion: $V(\phi)=V, 11-\cos \phi) / 2+V, 1-\cos 2 \phi) / 2$. The most stable conformation when $\mathrm{X}=\mathrm{OH}$ has $\mathrm{HO} \ldots \mathrm{OH}$ trans and the cis-trans energy difference is $0.07 \mathrm{kcal}$ mol ${ }^{-1}$. The a two-term Fourier expansion: $V(\phi)=V_{1}(1-\cos \phi) / 2+V_{2}(1-\cos 2 \phi) / 2$. The most stable conformation when $\mathrm{X}=\mathrm{O}$.
most stable conformation when $\mathrm{X}=\mathrm{CHO}$ has $\mathrm{HO} \ldots \mathrm{CO}$ cis and the cis-trans energy difference is $0.08 \mathrm{kcal}^{\mathrm{mol}}{ }^{-1}$. 


\section{DISCUSSION}

\section{A. The case for cyclohexane solution data}

It is well known that phenols are strongly associated in the liquid state and also undergo hydrogen bonding with other molecules and many solvents. With cyclohexane, there is no possibility of hydrogen bonding with the solvent $\dagger$, but solute-solvent interactions have been reported. V. von Keusler ${ }^{9}$ has shown that phenol in cyclohexane at a concentration of approximately $3 \times 10^{-4} \mathrm{~mol} / \mathrm{l}$. is completely monomeric but at a concentration of 0.15 $\mathrm{mol} / \mathrm{l}$. it is 52 per cent associated and 48 per cent monomer. Dearden and Forbes ${ }^{16}$ found an approximately $5 \mathrm{~m} \mu$ shift between the u.v. spectra of the vapour and $2.3 \times 10^{-4} \mathrm{~mol} / \mathrm{l}$. cyclohexane solutions which they attributed to solute-solvent interaction because phenol should be 100 per cent monomer at this concentration. Furthermore, Evans ${ }^{10}$ has noted the dependence of some infra-red band positions for phenol on the degree of association.

We have ruled out any large effect of association on the torsional frequency of phenol in cyclohexane solution for two reasons. First, we have compared the torsional frequencies of several halogen-substituted phenols obtained for cyclohexane solution with the corresponding vapour phase values of Fateley, Miller and Witkowski ${ }^{11}$. These data are given in Table 2. The agreement between solution and vapour values is almost perfect except for

Table 2. Torsional frequencies of halo-substituted phenols. Comparison of vapour and cyclohexane solution values

\begin{tabular}{lccc}
\hline Compound & Vapour $\left(\mathrm{cm}^{-1}\right)$ & $\mathrm{cm}^{-1}$ & $\begin{array}{c}\text { Concentration } \\
\text { (mol/1.) }\end{array}$ \\
\hline Phenol & 310 & 310 & 0.010 \\
-Fluorophenol & 280 & 280 & 0.009 \\
$p$-Chlorophenol & 302 & 302 & 0.015 \\
$m$-Fluorophenol & 311 & 329 \\
$m$-Chlorophenol & 319 & 316 & 0.009 \\
$m$-Bromophenol & 313 & 312 & 0.008 \\
\hline
\end{tabular}

* Doubling due to the presence of cis and trans forms. These totamers had previously been reported by us for metafluorobenzaldehyde.

meta-fluorophenol which is also peculiar in that the torsion is observed as a doublet in both solution and gas. Secondly, we have carried out a dilution study on phenol in cyclohexane solution to determine if there is any change in torsional frequency as a function of concentration. Over the concentration range 0.02 to $0.001 \mathrm{~mol} / 1$., which is the lower limit of detection with a $1 \mathrm{~cm}$ path length, the torsional frequency did not shift by more than $1 \mathrm{~cm}^{-1}$.

$\uparrow$ An exception to this observation may be the ortho-fluorophenol which might be intermolecularly hydrogen bonded. 
These two observations are taken as strong indication that for phenol in cyclohexane at concentrations below $0.02 \mathrm{~mol} / \mathrm{l}$., association effects on the torsional frequency are negligible. Furthermore, the good agreement of solution and vapour data also seems to rule out any appreciable effect of solvent-solute interaction.

Similar agreement between solution and vapour phase torsional frequencies can also be seen in the data on thiols and amines given by Scott and Crowder ${ }^{12}$. The solvents used in their work were cyclopentane and 2,2,4-trimethylpentane; however, it should be noted that not all solvents show this behaviour. Phenol in benzene solution, for example, shows no evidence for the $310 \mathrm{~cm}^{-1}$ torsional frequency.

\section{B. Calculation of the barrier to internal rotation from the observed torsional frequency for phenol}

The internal rotation barrier for phenol has been treated in great detail using both microwave ${ }^{13}$ and infra-red ${ }^{11,14}$ data. It is well established that the $\mathrm{O}-\mathrm{H}$ group lies in the plane of the benzene ring and hence the hindering potential can be written in the form

$$
V=\frac{1}{2} V_{2}(1+\cos 2 \alpha)+\frac{1}{2} V_{4}(1+\cos 4 \alpha)+\ldots
$$

where $V_{2}$ and $V_{4}$ are the heights of the twofold and fourfold barriers and $\alpha$ is the torsional angle which is $\pi / 2$ in the planar configuration. The torsional energy for each torsional quantum number, $v$, is

$$
E_{v, \sigma}=(n / 2)^{2} F b_{v, \sigma}
$$

and the energy solution gives + and - sublevels for each $v$. In the above equations: $v$ is the principal torsional quantum number, $\sigma$ is the index designating + and - levels, $b_{v \sigma}$ is an eigenvalue of the Mathieu equation, $F=h^{2} / 8 \pi^{2} r I_{\alpha}, r I_{\alpha}$ is the reduced moment of inertia for internal rotation, $I_{\alpha}$ is the moment of inertia of the internal top $(\mathrm{O}-\mathrm{H}$ group) about its symmetry axis, $n$ denotes the $n$-fold barrier (in this case $n=2$ ), and $V_{4}= \pm 0.01 V_{2}$ (experimental observation).

The observed infra-red torsional frequency, $\omega_{\tau}$, gives the difference between two of the energy levels, $\Delta E_{v \sigma}$

$$
\omega_{\tau}=(n / 2)^{2} F\left(\Delta b_{v \sigma}\right)=\Delta E_{v \sigma}
$$

Thus, if $\omega_{\tau}$, the torsional frequency, is known and there is enough structural information to determine $F\left(=h^{2} / 8 \pi^{2} r I_{\alpha}\right), \Delta b_{v \sigma}$ can be calculated. From $\Delta b_{v \sigma}$, a parameter, $s$, can be obtained from Mathieu equation solution tables. The barrier height is then

$$
V_{2}=F s
$$

Thus, if the torsional frequency can be measured accurately, the evaluation of $V_{2}$ is straightforward provided $I_{\alpha}$ can be calculated from known structural information.

The geometry of the $\mathrm{O}-\mathrm{H}$ rotor relative to the symmetry axis appears to be the only problem in the calculation of $I_{\alpha}$. Bist et al. ${ }^{14}$, in order to fit their data for both phenol and phenol-OD, were forced to conclude that the oxygen atom assumed an off-axis position 


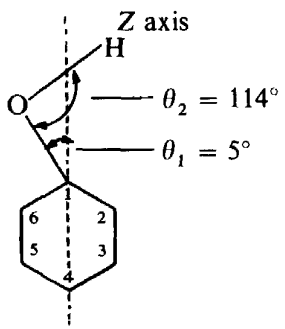

Mathieu et al. ${ }^{13}$, through the analysis of new microwave data by rotationinternal rotation theory, find that the frame principal axis is within $\pm 0.18^{\circ}$ parallel to the internal rotation axis. These authors also point out that the relatively large errors in their microwave constants originate mainly in the limited precision of the infra-red data which in this case were due to Bist et al. ${ }^{14}$.

We feel that our present data on phenol will, at least, partially resolve these discrepancies and support the evidence that the $\mathrm{C}-\mathrm{O}$ rotor axis is coincident with the frame principal axis. These data are given in Table 3 and compared with the data of Bist et al. ${ }^{14}$.

Table 3. Far infra-red spectra of phenol and phenol-OD

\begin{tabular}{|c|c|c|c|c|}
\hline \multicolumn{2}{|c|}{ Phenol $\left(\mathrm{cm}^{-1}\right)$} & \multicolumn{2}{|c|}{ Phenol-OD $\left(\mathrm{cm}^{-1}\right)$} & \multirow[b]{2}{*}{$\begin{array}{l}\text { Assignment/ } \\
\text { comment }\end{array}$} \\
\hline $\begin{array}{l}\text { Bist }^{1}, \\
\text { vapour }\end{array}$ & $\begin{array}{c}\text { This work, } \\
\text { solution }\end{array}$ & $\begin{array}{l}\text { Bist }^{1} \\
\text { vapour }\end{array}$ & $\begin{array}{c}\text { This work, } \\
\text { solution }\end{array}$ & \\
\hline 408 & - & 382 & 388 & $V_{18 b}\left(b_{2}\right) x$-sens \\
\hline 309.6 & 310 & - & $\ldots$ & $\mathrm{O}-\mathrm{H}$ torsion $0 \rightarrow 1$ \\
\hline $\left.\begin{array}{l}278.0 \\
276.2\end{array}\right\}$ & 282 & - & - & $1 \rightarrow 2$ \\
\hline $\left.\begin{array}{l}253.0 \\
237.0\end{array}\right\}$ & 232 & - & - & $2 \rightarrow 3$ \\
\hline $244^{*}$ & $\cdots$ & 246.4 & 247 & $V_{11}\left(b_{1}\right) x$-sens. \\
\hline- & - & $\left.\begin{array}{l}228.4 \\
228.4 \\
233\end{array}\right\}$ & $212\}$ & See text \\
\hline
\end{tabular}

* Raman value- $\mathrm{CCl}_{4}$ solution.

Bist has assigned the 246-228 bands as the $0 \rightarrow 1$ and $1 \rightarrow 2$ transitions of the $\mathrm{O}-\mathrm{D}$ torsion and the $232 \mathrm{~cm}^{-1}$ band as the $x$-sensitive $V_{11}\left(b_{1}\right)$ mode. These authors also note that their data do not lead to the expected shift of $\sqrt{ } 2$ in the reduced moment of inertia on going from $\mathrm{O}-\mathrm{H}$ to $\mathrm{OD}$ and ascribe this to a change in geometry. Our solution data indicate that there is a second, intense band at $212 \mathrm{~cm}^{-1}$ which was below the range of their instrument. Our data on phenol-OD, as well as data on other phenols to be discussed later, show that the $247 \mathrm{~cm}^{-1}$ band is not the $0 \rightarrow 1$ transition for the $\mathrm{O}-\mathrm{D}$ torsion $\left(b_{1}\right)$ but is one branch of a Fermi doublet arising from resonance between the $\mathrm{O}-\mathrm{D}$ torsion and the $x$-sensitive $V_{11}\left(b_{1}\right)$ mode near $233 \mathrm{~cm}^{-1}$. This would then place the $\mathrm{O}-\mathrm{D}$ torsional frequency near 230 
$\mathrm{cm}^{-1}$ which gives a $v_{\mathrm{O}-\mathrm{H}} / v_{\mathrm{O}-\mathrm{D}}=310 / 230=1.35$ in good agreement with ratios found for the torsions in most of the phenols investigated. This reassignment of the phenol-OD torsion could remove some of the inconsistencies noted by Mathieu ${ }^{13}$, and also makes it unnecessary to assume the geometry of the rotor proposed by Bist ${ }^{14}$.

Also additional observation of transition between higher energy levels in several phenols, i.e. the hot bands $1 \rightarrow 2$ and $2 \rightarrow 3$, provides adequate information concerning the $V_{4}$ value. Usual values of $V_{4}$ in the range of $\pm 0.01 V_{2}$ are small enough to be neglected in these studies.

\section{EXPERIMENTAL PROCEDURES}

The various phenol samples were obtained from several sources and were purchased in the highest purity available $\uparrow$. Usually, the samples were used without further purification. Because the torsional band is, in general, much more intense in dilute solution than the other bands in the far infra-red region for these compounds, it is felt that small amounts of impurities would not interfere.

The phenol-OD analogues were prepared by deuterating the $\mathrm{OH}$ compound directly in solution with $\mathrm{D}_{2} \mathrm{O}$ by a technique described elsewhere ${ }^{15}$.

Far infra-red spectra were obtained on a Digilab FTS-14 interferometer system. A $6 \mu \mathrm{m}$ mylar beamsplitter was used to cover the range 450 to 75 $\mathrm{cm}^{-1}$, and for most samples the resolution was $8 \mathrm{~cm}^{-1}$. This instrument is ideally suited to this type of study because of its ability to ratio out solvent backgrounds even with the low energy available in the far infra-red region.

Cells equipped with $1 / 16$ in. polypropylene windows were employed and the path length was generally $5 \mathrm{~mm}$ although for a few samples a $10 \mathrm{~mm}$ path length was necessary. A compensating cell was used in the reference beam to ratio out absorption due to the solvent and windows.

\section{RESULTS}

The observed torsional frequencies and calculated barriers to internal rotation for several monosubstituted phenols are given in Table 4. Also presented in Table 4 is the difference in the torsional frequency, $\Delta \omega_{r}$, for these compounds compared to the phenol torsion at $310 \mathrm{~cm}^{-1}$. That is

$$
\begin{aligned}
\Delta \omega_{\tau} & =\omega_{\tau}^{\text {obs }}-\omega_{\tau}^{\text {phenol }} \\
& =\omega_{\tau}^{\text {obs }}-310 \mathrm{~cm}^{-1}
\end{aligned}
$$

These values are presented in Table 4.

Commercial samples were purchased from Eastman, Aldrich, Pfaltz and Bauer, and ChemService, Inc. We are indebted to Dr A. W. Baker of The Dow Chemical Co., Walnut Creek, California for a number of custom synthesized phenols. 


\section{BARRIERS AND CONFORMATIONS}

Table 4. Observed torsional frequencies $\left(\omega_{\mathrm{t}}\right)$, barriers to internal rotation $\left(V_{2}\right.$, in $\mathrm{cm}^{-1}$ and $\mathrm{kcal} / \mathrm{mol})$, and $\Delta \omega_{\tau}$ shift from phenol for various monosubstituted phenols

\begin{tabular}{|c|c|c|c|c|}
\hline \multirow{2}{*}{$\begin{array}{l}\text { Phenolic } \\
\text { compound }\end{array}$} & \multirow{2}{*}{$\begin{array}{c}\omega_{\tau^{\prime}} \\
\mathrm{cm}^{-1}\end{array}$} & \multicolumn{2}{|c|}{$V_{2}$} & \multirow{2}{*}{$\begin{array}{l}\Delta \omega_{\tau_{1}}, \\
\mathrm{~cm}^{-}\end{array}$} \\
\hline & & $\mathrm{cm}^{-1}$ & $\mathrm{kcal} / \mathrm{mol}$ & \\
\hline$p$-Fluoro & 280 & 1034 & 2.96 & -30 \\
\hline -Chloro & 302 & 1185 & 3.30 & -8 \\
\hline -Bromo & 303 & 1193 & 3.41 & -7 \\
\hline -Iodo & 313 & 1266 & 3.50 & +3 \\
\hline -Methyl & 295 & 1135 & 3.24 & -15 \\
\hline -Methoxy & 268 & 954 & 2.73 & -42 \\
\hline - $t$-Butyl & 301 & 1178 & 3.37 & -9 \\
\hline -Phenyl & 310 & 1244 & 3.56 & 0 \\
\hline -Nitro & 350 & 1588 & 4.54 & +40 \\
\hline -n-Butoxy & 268 & 954 & 2.73 & -42 \\
\hline -Cyanide & 343 & 1492 & 4.264 & +33 \\
\hline -Methyl & 295 & 1134 & 3.24 & -15 \\
\hline \multirow{2}{*}{\multicolumn{5}{|c|}{ m-Fluoro }} \\
\hline & 329 & 1389 & 3.97 & +19 \\
\hline trans & 316 & 1289 & 3.68 & +6 \\
\hline -Chloro & 312 & 1258 & 3.60 & +2 \\
\hline -Bromo & 312 & 1258 & 3.60 & +2 \\
\hline -Iodo & 313 & 1266 & 3.62 & +3 \\
\hline -Methyl & 312 & 1258 & 3.60 & +2 \\
\hline -Methoxy & 317 & 1296 & 3.70 & +7 \\
\hline -Cyanide & 316 & 1289 & 3.68 & +6 \\
\hline -Nitro & 320 & 1318 & 3.77 & +10 \\
\hline -Phenyl & 310 & 1244 & 3.56 & 0 \\
\hline$-t$-Butyl & 304 & 1200 & 3.43 & -6 \\
\hline -Hydroxy & 318 & 1304 & 3.73 & +8 \\
\hline \multirow{2}{*}{$\begin{array}{r}o \text {-Cyanide, bonded } \\
\text {, unbonded }\end{array}$} & 393 & 1932 & 5.52 & +83 \\
\hline & 376 & 1782 & 5.09 & +67 \\
\hline -Fluoro & 366 & 1694 & 4.84 & +56 \\
\hline -Chloro, bonded* & 396 & 1965 & 5.62 & +87 \\
\hline , unbonded & 361 & 1660 & 4.74 & +52 \\
\hline -Bromo, bonded* & 395 & 1949 & 5.57 & +82 \\
\hline . unbonded & 361 & 1643 & 4.70 & +50 \\
\hline -lodo, bonded* & 378 & 1826 & 5.22 & +68 \\
\hline , unbonded & 345 & 1526 & 4.36 & +35 \\
\hline
\end{tabular}

* Bonded indicates the intramolecular bond with the halogen (See ref. 16).<smiles>[X][C]1[CH]CCCC1</smiles>

Bonded<smiles>[X]C1CCCCC1O</smiles>

Unbonded

Now, if the substituents represent linear mesomeric and inductive effects, i.e. each substituent in a specific position always influences the $\pi$ bonding with the same magnitude, then we should be able to use the values in Table 4 to predict the torsional frequencies and barriers for multisubstituted phenols. 


\section{WILLIAM G. FATELEY}

For example, the torsional vibration of the non-bonded 2,4,5-trichlorophenol should be the linear combination of the values in Table 4. Summarizing $\omega_{\tau}^{\text {calc }}=\omega_{\tau}^{\text {phenol }}+\left(\Delta \omega_{\tau}\right)_{\mathrm{Cl}}^{\text {ortho }}+\left(\Delta \omega_{\tau}\right)_{\mathrm{Cl}}^{\text {para }}+\left(\Delta \omega_{\tau}\right)_{\mathrm{Cl}}^{\text {meta }}$. Substituting the values from Table 4, we obtain

$$
\begin{aligned}
\omega_{\tau}^{\text {calc }}=310 \mathrm{~cm}^{-1}+\left(+52 \mathrm{~cm}^{-1}\right)_{\mathrm{Cl}}^{\text {ortho }} & +\left(-8 \mathrm{~cm}^{-1}\right)_{\mathrm{Cl}}^{\text {para }} \\
& +\left(+2 \mathrm{~cm}^{-1}\right)_{\mathrm{Cl}}^{\text {meta }}=356 \mathrm{~cm}^{-1}
\end{aligned}
$$

The observed torsional frequency of the unbonded 2,4,5-trichlorophenol is $354 \mathrm{~cm}^{-1}$. A summary of this calculation for several phenols is given in Table 5. We are very gratified to find the good to excellent agreement between

\begin{tabular}{|c|c|c|c|c|}
\hline \multirow[b]{2}{*}{ Compound } & \multicolumn{3}{|c|}{ Torsion } & \multirow[b]{2}{*}{ Comment } \\
\hline & Obs. & Calc. & Diff. $\%$ & \\
\hline \multicolumn{5}{|l|}{ 1. Di-substituted } \\
\hline 2,3-Dimethyl & 308 & 304 & -1.3 & \\
\hline 3,5-Dimethyl & 312 & 312 & 0 & \\
\hline 2,6-Dimethyl & 303 & 302 & -0.3 & \\
\hline 3,4-Dimethyl & 298 & 297 & -0.3 & \\
\hline \multirow{2}{*}{ 3-Methyl-6-chloro } & $\{397$ & 397 & 0 & Bonded form \\
\hline & 367 & 364 & -0.8 & Free form \\
\hline 3-Methyl-4-chloro & 305 & 304 & -0.3 & \\
\hline \multirow{2}{*}{ 2,4-Dichloro } & $\{389$ & 389 & 0 & Bonded form \\
\hline & $\{354$ & 354 & 0 & Free form \\
\hline \multirow{2}{*}{ 2-Bromo-4-chloro } & $\int 387$ & 387 & 0 & Bonded form \\
\hline & 354 & 352 & -0.6 & Free form \\
\hline \multirow{2}{*}{ 2-Chloro-4-fluoro } & 370 & 367 & -0.8 & Bonded form \\
\hline & 336 & 332 & -1.2 & Free form \\
\hline 2-Fluoro-4-nitro & 395 & 396 & +0.3 & \\
\hline 3,5-Di-t-butyl & 304 & 304 & 0 & \\
\hline \multicolumn{5}{|l|}{ 2. Tri-substituted } \\
\hline 2.4.6-Tribromo & 392 & 388 & -1.0 & Bonded \\
\hline 2,4,6-Trichloro & 393 & 389 & -1.0 & Bonded \\
\hline 2,4.6-Triiodo & 382 & 383 & +0.3 & Bonded \\
\hline 2.6-Dichloro-4-bromo & 396 & 388 & -2.0 & Bonded \\
\hline 2-Br-4,6-Dichloro & 393 & 388 & -1.3 & Bonded using $o$-chloro value \\
\hline \multirow{2}{*}{ 2,4,5-Trichloro } & $\{389$ & 391 & +0.5 & Bonded \\
\hline & $\{353$ & 356 & +0.8 & Free \\
\hline 2,6-Dibromo-4-methyl & 388 & 380 & -2.0 & Bonded form \\
\hline 2,6-Dichloro-4-nitro & 432 & 437 & +1.2 & Bonded form \\
\hline 2,6-Dibromo-4-nitro & 432 & 435 & +0.7 & Bonded form \\
\hline 2,6-Diiodo-4-nitro & 417 & 420 & +0.7 & Bonded form \\
\hline 2,6-Dichloro-4-hydroxy & 360 & $(360)$ & 0 & Predicts $p-\mathrm{OH}$ shift $=-37$ \\
\hline 2,6-Dimethyl-4-methoxy & 254 & 260 & +2.0 & $\begin{array}{l}254 \text { calc. from OD. Fermi res. } \\
\text { in } \mathrm{OH} \text { compound? }\end{array}$ \\
\hline \multicolumn{5}{|l|}{ 3. Other substituted } \\
\hline Pentachloro & 394 & 391 & -0.8 & \\
\hline
\end{tabular}

Table 5. Observed versus calculated torsions 
calculated and observed torsional frequencies. This confirms our suspicion that these mesomeric and inductive effects are linear and can be predicted for many molecules from the data in Table 4.

These values can be used to predict chemical properties much like Hammett's $\sigma$ s have been used in the past. We feel the $\Delta \omega_{\mathrm{r}}$ better reflects the aromatic climate of the ring and will give yet another, and we feel better, parameter for the use of the chemist. This can further be extrapolated to predict bond parameters of aromatic rings in polymer chains.

\section{PART I. REFERENCES}

1 W. J. Hehre, L. Radom and J. A. Pople, J. Amer. Chem. Soc., in press.

2 T. Kojima, J. Phys. Soc. Japan, 15, 284 (1960).

3 A. Hall and J. L. Wood, unpublished results quoted in G. E. Campagnaro and J. L. Wood, J. Molec. Structure, 6, 117 (1970).

4 For details see G. L. Carlson, W. G. Fateley and F. F. Bentley, Spectrochim. Acta, 28A, 177-179 (1972).

5 C. J. Roothaan, Rev. Mod. Phys, 23, 69 (1951).

6 W. J. Hehre, R. F. Stewart and J. A. Pople, J. Chem. Phys. 51, 2657 (1969).

7 J. A. Pople and M. S. Gordon, J. Amer. Chem. Soc. 89, 4253 (1967).

8 R. S. Mulliken, J. Chem. Phys. 23, 1833 (1955).

9 V. von Keusler, Z. Elektrochem. 58, 136 (1954).

10 J. C. Evans, Spectrochim. Acts, 16, 1382 (1960).

11 W. G. Fateley, F. A. Miller and R. E. Witkowski, Technical Report, Air Force Materials Laboratory, AFML-TR-66-408, January 1967, Wright-Patterson Air Force Base, Ohio.

12 D. W. Scott and G. A. Crowder, J. Molec. Spectrosc. 26, 477 (1968).

13 E. Mathieu, D. Welti, A. Bander and Hs. H. Günthard, J. Molec. Spectrosc. 37, 63 (1971).

14 H. D. Bist, J. C. D. Brand and D. R. Williams, J. Molec. Spectrosc. 24, 402 (1967).

15 H. D. Bist, J. C. D. Brand and D. R. Williams, J. Molec. Spectrosc. 24, 413 (1967).

16 G. L. Carlson, W. G. Fateley, A. S. Manocha and F. F. Bentley, J. Phys. Chem. 76, 1553 (1972).

Part II

Far-Infra-red Investigation of Internal Rotation about Single Bonds (In collaboration with Mr A.S. Manocha and Dr E. Tuazon)

\section{INTRODUCTION}

In order to understand internal rotation in macromolecules, we must have a better understanding of potentials surrounding such units as carbon-carbon, carbon-oxygen, carbon-nitrogen and carbon-sulphur single bonds. A far infra-red investigation with emphasis on the evaluation of the asymmetric potential function should yield the desired barrier characteristic of these units. This part describes this investigation.

\section{BACKGROUND}

A large body of experimental data on the subject of internal rotation has been accumulated over the past ten years ${ }^{1}$. However, most of these data deal with barrier parameters for a highly symmetrical internal rotor, namely, the methyl group. Much work still remains to be done on molecules containing asymmetric rotors. A number of determinations have been carried 
out on molecules with asymmetric rotors by microwave spectroscopy ${ }^{1}$, but in only a few cases has the potential function been fully characterized ${ }^{2}$. Oftentimes, these measurements are accompanied by large uncertainties in the calculated barrier parameters. These large errors arise when the microwave measurements rely heavily on comparison of intensities between rotational lines in calculating the positions of the different torsional levels. Because of the vibrational nature of the internal rotation (torsion), far-infra-red spectroscopy is the most direct and the more accurate technique for such studies provided sufficient transitions between the torsional levels of a molecule are observed.

Increasing efforts are now being exerted on the correlation of existing data with the ultimate objective of explaining the source of the barrier to internal rotation $^{1 \mathrm{a}, 3}$. In Part I, we described the theoretical calculation of barriers in phenols by Professor Pople's group and the experimental confirmation of these barriers by far-infra-red spectroscopy. This represents a portion of our goal toward understanding barriers. It is along this line that an evaluation of potential functions for asymmetric rotors is of particular merit. It has been pointed out by Lowe ${ }^{1 \mathrm{a}}$ that such results will constitute a more rigorous test for a theory than barrier values for methyl rotors. This is because in theoretical calculations of barriers. the symmetry of the methyl group may force a great deal of error cancellation whereas such errors will still be highly evident for asymmetric rotors.

In both experimental and theoretical determinations, the general Fourier series $V(\alpha)=\sum_{n} a_{n} \cos n \alpha+\sum_{n} b_{v} \sin n \alpha$ has been widely applied for the potential function of internal rotation. For cases where the potential is an even function of the torsional angle $\alpha$, the form is reduced to a cosine series only, i.e. $V(\alpha)=\frac{1}{2} \sum_{n} V_{n}(1-\cos n \alpha)$. An interesting suggestion is that the

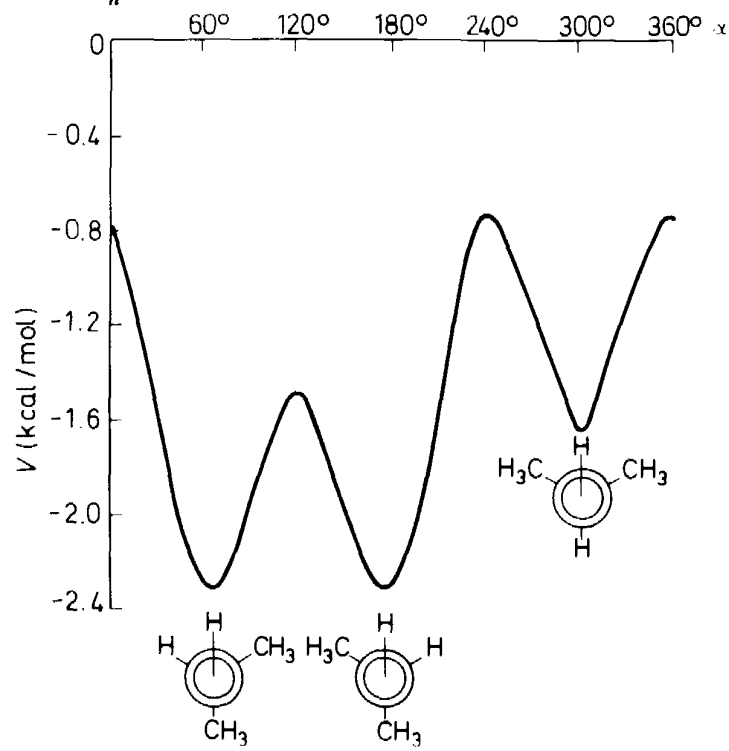

Figure 1. Predicted potential curve for isopropyl alcohol. 


\section{BARRIERS AND CONFORMATIONS}

interaction between an atom or substituent in an internal rotor and the frame may be individually expressed as a Fourier series, each type of interaction being additive. If proven to be valid, such an approach will be very useful in predicting the form of the potential curve for internal rotation. Predictions on this basis were made by Stiefvater and Wilson ${ }^{2 b}$ for methyland fluoro-substituted acetyl fluorides but no experimental confirmation has yet been made.

We have applied the method of Stiefvater and Wilson ${ }^{2 b}$ to some molecules of interest in this research to see what might be the approximate form of the potential curve associated with internal rotation. Due to lack of any experimental data, we used the theoretical results of Radom, Hehre and Pople ${ }^{3}$ on monomethyl- and monofluoro-substituted methanols and methylamines. These authors' results for the internal rotation around the $\mathrm{C}-\mathrm{O}$ and $\mathrm{C}-\mathrm{N}$ bonds, using the Fourier cosine form for the potential, are summarized below:

\begin{tabular}{lccc}
- & & $(\mathrm{kcal} / \mathrm{mol})$ & \\
Molecule & $V_{1}$ & $V_{2}$ & $V_{3}$ \\
\hline $\mathrm{CH}_{3}-\mathrm{OH}$ & 0 & 0 & -1.12 \\
$\mathrm{CH}_{3} \mathrm{CH}_{2}-\mathrm{OH}$ & -0.93 & -0.05 & -1.14 \\
$\mathrm{FCH}_{2}-\mathrm{OH}$ & 5.25 & -2.20 & -0.96 \\
$\mathrm{CH}_{3}-\mathrm{NH}_{2}$ & 0 & 0 & -2.13 \\
$\mathrm{CH}_{3} \mathrm{CH}_{2}-\mathrm{NH}_{2}$ & 0.89 & 0.21 & -2.29 \\
$\mathrm{FCH}_{2}-\mathrm{NH}_{2}$ & -4.86 & 4.28 & -2.01 \\
\hline
\end{tabular}

It is seen that the value of $V_{3}$ for each series of molecules given above remains approximately constant, perhaps well within the error due to the uncertainty in the molecular geometries used in the calculation. This near constancy of $V_{3}$ has also been observed in the substituted acetyl fluorides ${ }^{2 b}$. Thus, in ethanol, the effect of a methyl substitution on the different potential constants can be expressed as follows:

$$
\begin{aligned}
& V_{3}^{\mathrm{CH}_{3} / \mathrm{H}} \sim 0 \\
& V_{1}^{\mathrm{CH}_{3} / \mathrm{H}}=-0.93 \\
& V_{2}^{\mathrm{CH}_{3} / \mathrm{H}}=-0.05
\end{aligned}
$$

The potential curve for isopropyl alcohol may then be synthesized by superimposing the expansion $\left[\frac{1}{2} V_{1}(1-\cos \alpha)+\frac{1}{2} V_{2}(1-\cos 2 \alpha)\right]^{\mathrm{CH}_{3} / \mathbf{H}}$ over the expansion $\left\{\frac{1}{2} V_{1}[1-\cos (\alpha+2 \pi / 3)]+\frac{1}{2} V_{2}[1-\cos 2(\alpha+2 \pi / 3)]\right\}^{\mathrm{CH}_{3} / \mathrm{H}}$ and adding the basic $V_{3}$ term. The average values of $V_{3}=-1.1 \mathrm{kcal} / \mathrm{mol}$ and $V_{3}=-2.1 \mathrm{kcal} / \mathrm{mol}$ were assumed for the methanol and methylamine series, respectively. The resulting potential curve for isopropyl alcohol is given in Figure 1. Results of similar calculations on isopropyl amine and 1-fluoroethanol are presented in Figures 2 and 3. 


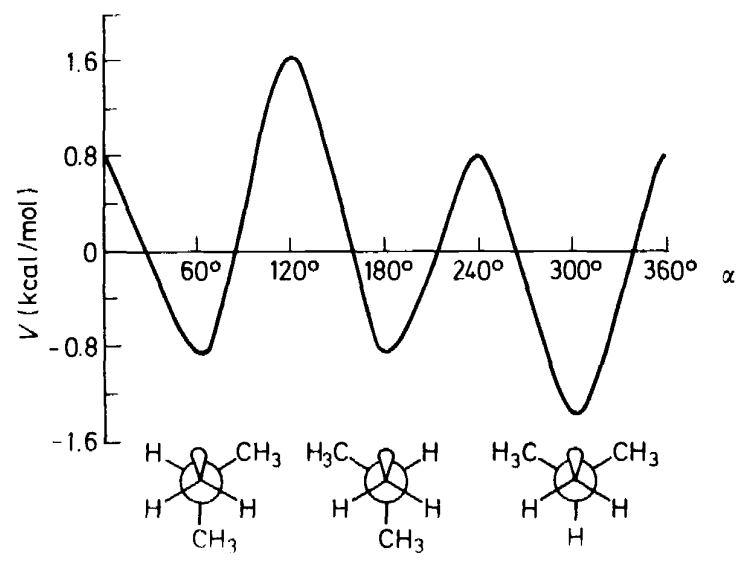

Figure 2. Predicted potential curve for isopropyl amine.

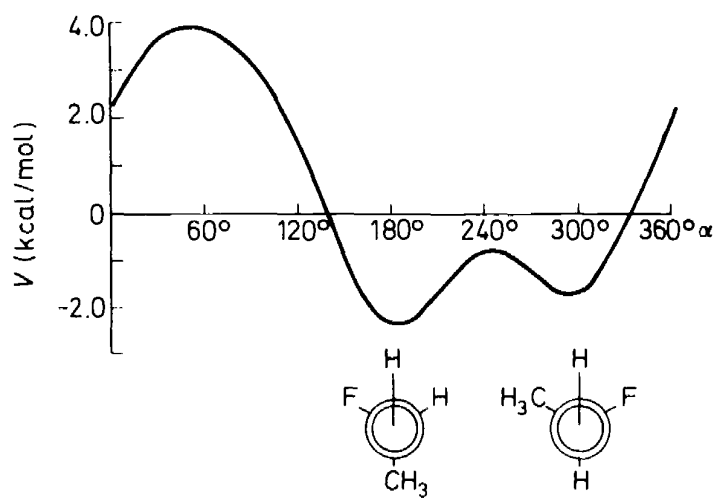

Figure 3. Predicted potential curve for 1-fluoroethanol.

While the above calculations are certainly approximate, experimental verification indicates they are correct. This allows us to anticipate that isopropyl alcohol and isopropyl amine, like ethanol ${ }^{4}$ and ethylamine ${ }^{5}$, may exist in the respective trans and gauche rotamers in measurable proportions. Experimental results on similar larger molecules demonstrated this approximation.

\section{EXPERIMENTAL}

The far-infra-red spectra of several of the above-mentioned molecules have been measured and the torsional vibrations located for the $\mathrm{C}-\mathrm{C}, \mathrm{C}-\mathrm{O}$, $\mathrm{C}-\mathrm{N}$ and $\mathrm{C}-\mathrm{S}$ bonds. As mentioned earlier, as many transitions between torsional levels as possible must be measured for an accurate characterization of the potential curve. The fulfilment of this requirement is favoured by the low-frequency nature of most torsional vibrations. 


\section{BARRIERS AND CONFORMATIONS}

The spectra will be recorded in this laboratory's newly acquired DIGILAB FTS-14 infra-red Fourier transform spectrophotometer. The maximum resolution capability of this instrument is $0.5 \mathrm{~cm}^{-1}$ throughout the region 10 to $4000 \mathrm{~cm}^{-1}$. Interchangeable mylar beam splitters of various thicknesses permit the entire far-infra-red range to be examined. All measurements were carried out in the gas phase to permit higher resolution and accuracy in measuring band centres. Our laboratory is equipped with a heated 1-meter cell, a $10-\mathrm{cm}$ gas cell, and various home-built short-path cells. For resolutions of 1 and $0.5 \mathrm{~cm}^{-1}$ in the far-infra-red region, it was found necessary to use wedged polyethylene or polypropylene cell windows to eliminate fringes.

The assignment of the torsional frequencies in $\mathrm{C}-\mathrm{OH}, \mathrm{C}-\mathrm{NH}_{2}$ and $\mathrm{C}-\mathrm{SH}$ compounds was verified by a solution technique developed in this laboratory ${ }^{6}$. A dilute solute solution of an alcohol or amine in cyclohexane (about one per cent) is made and to this is added a few drops of $\mathrm{D}_{2} \mathrm{O}$. The ensuing substitution of the labile hydrogen atom by deuterium permits the measurement of shifts in the torsional frequencies resulting from deuteration.

It is not uncommon that a torsional band is obscured by overlapping with another broad low-frequency band (e.g. methyl torsion) in which case the vapour-phase spectrum of the compound deuterated at the functional position was useful. Such preparation is easily made through exchange reaction in an excess of $\mathrm{D}_{2} \mathrm{O}$ and separation by distillation. Several deuterated forms of ethanol and ethylamine were purchased for this study.

\section{INTERPRETATION OF DATA}

For the molecules of interest here, the Fourier cosine series, $V(\alpha)=\frac{1}{2} \sum_{n} V_{n}$ $(1-\cos n \alpha)$, was adequate to represent the potential associated with internal rotation. It has been found that, in general, the series converges rapidly with $n=3$ or 4 being sufficient to explain the spectroscopic data. The wave equation for the internal rotation problem is a Mathieu-type equation in one dimension

$$
\left[p_{\alpha} F(\alpha) p_{\alpha}+V(\alpha)\right] M(\alpha)=E M(\alpha)
$$

where $F(\alpha)$ is the reduced moment of inertia parameter, $p_{\alpha}$ is the momentum conjugate to $\alpha, E$ is the energy eigenvalue, and $M(\alpha)$ is a function expressed as an expansion in some chosen basis set.

A computer programme has been written ${ }^{7}$ which utilizes the free-rotor functions $\exp \operatorname{im} \alpha$ as the basis set for calculating the matrix elements, i.e. $M_{n}(\alpha)=\sum_{n} a_{n m} \exp \operatorname{im} \alpha$. The size of the basis set can be varied and it is determined through the convergence of eigenvalues at a particular energy level. The variation of the inertial parameter $F$ with the angle of internal rotation has been included by incorporating a programme written by Meakin $e t$ al. ${ }^{2 a}$ for such purpose. The complete programme has been tested with the known data on molecules with asymmetric rotors like $\mathrm{H}_{2} \mathrm{O}_{2}{ }^{8}$, as well as on those containing symmetrical rotors (e.g. methyl group). The procedure consists of making a judicious choice of an initial set of potential constants $V_{n}$ and comparing the calculated eigenvalue differences with the observed frequencies. The values of $V_{n}$ are then refined to give the best fit to the observed data through an iterative numerical procedure. 
We have carried out a zero-order calculation on ethanol using the theoretical values of $V_{1}, V_{2}$ and $V_{3}$ given by Radom, Hehre and Pople ${ }^{3}$. The small variation of the reduced moment of inertia of the $\mathrm{OH}$ group with the internal angle was neglected; thus, a constant value $F=21 \mathrm{~cm}^{-1}$ was calculated from an approximate geometry. The predicted energy levels for ethanol are depicted in Fiqure 4 ( $n$ is just a number that gives the order of the levels). The first

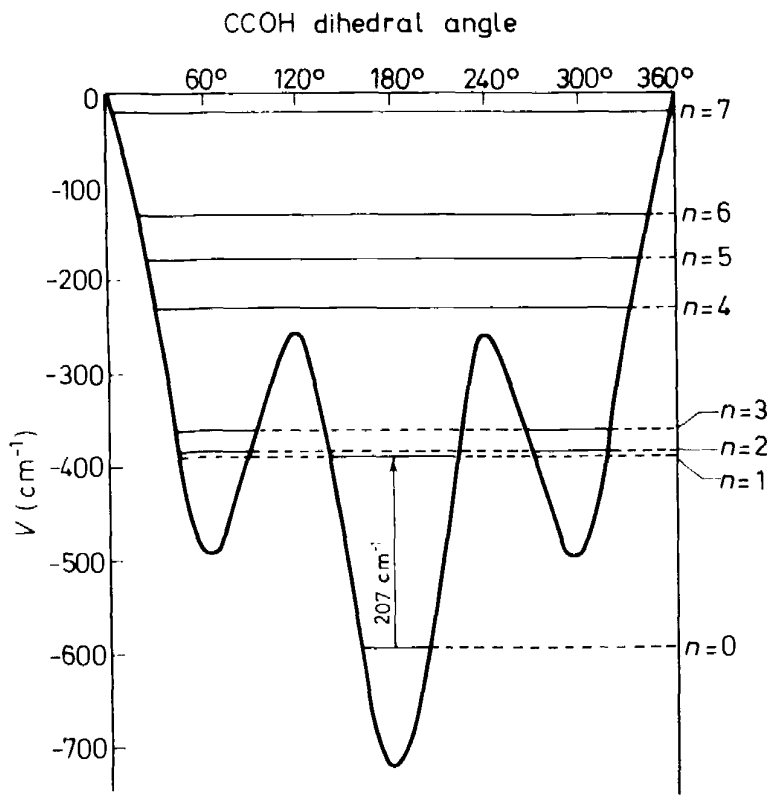

Figure 4. Predicted energy levels for ethanol.

two levels, assigned to the trans form, have an energy separation of $207 \mathrm{~cm}^{-1}$. Lake and Thompson ${ }^{9}$ observed the torsional band of ethanol in the vapour phase under low resolution and reported the centre of the broad band at $199 \mathrm{~cm}^{-1}$. The measured band contour indicates that, under higher resolution, the transitions between the upper torsional levels might be observed. These higher transitions allow a more accurate determination of the potential constants.

\section{THE EFFECT OF HIGHER TERMS AND VARIATION OF THE INERTIAL PARAMETER ON THE THREEFOLD POTENTIAL FUNCTION}

In most determinations of the threefold barrier $V_{3}$ for the methyl groups, the next higher potential constant $V_{6}$ in the cosine series expansion has been neglected. While the values of $V_{6}$ have indeed been found to be generally small (about one per cent of $V_{3}$ ), their accurate determination, particularly their sign. will be useful in distinguishing between various theories on the source of barrier in methyl rotors ${ }^{1 \mathrm{a}}$. In their semiempirical electrostatic 
model for internal rotation, Lowe and $\operatorname{Parr}^{10}$ pointed out that a negative $V_{6}$ is connected with those charges and multipoles (situated in the plane containing the heavy atoms) which repel methyl protons, while a positive $V_{6}$ is produced by those charges and multipoles (in the plane) which attract the methyl group.

In nearly all calculations on threefold potential, the variations of the reduced moment of inertia of the top $(F)$ during the torsional motion, such as those which arise from bond stretching and angle deformation, have been neglected. Recently, Ewig and Harris ${ }^{11}$ demonstrated that such assumption of constant results in an apparent $V_{6}$ component in the potential even if none, in fact, existed. These authors also emphasized that it is not possible to distinguish between the effect of a variation in the reduced moment of inertia of the top and contribution of higher terms to the threefold potential.

Harris et al. ${ }^{12}$ showed that the Hamiltonian $H(\alpha)=p_{\alpha} F(\alpha) p_{\alpha}+V(\alpha)$, expressed in the geometry related coordinate $\alpha$, may be transformed to the form $H(\theta)=p_{\theta} F_{0} p_{\theta}+V^{\prime}(\theta)$ where $\theta$ is a coordinate which removes the angle dependence of $F$. The coordinate $\theta$ has no attachable geometrical meaning and only follows the condition that it be equal to $\alpha$ at 0 and $2 \pi$ radians. The two forms of the Hamiltonian give the same eigenvalues. The transformation from $\alpha$ to $\theta$ produces a distortion relative to the coordinate (shifts in the position of maxima and minima and change in shape of the potential curve) but does not affect the height of the barrier. In the special case of the methyl rotor, symmetry dictates that $\alpha$ and $\theta$ be the same at the positions of maxima and minima and the only question that arises is how both $F$ and $V_{6}$ augment the shape of the potential curve.

We must note in applying these theories to macromolecules that some attention be directed to the study of $F$ and $V_{6}$ dependence of the threefold potential. Several molecules with methyl rotors and with well-determined geometry in the ground vibrational state were chosen for this evaluation. Their far infra-red spectra were recorded with the object of measuring as many transitions between torsional levels as possible. The task of making the choice of these molecules is made easier by earlier measurements in this laboratory ${ }^{13}$. With better instruments available to us now, improved spectra in terms of resolution and frequency accuracy show these splittings of energy levels.

Although there is an apparent inseparability of the $F$ and $V_{6}$ effects, much information has been gained by the following simple approach. In the first step, a fit of the observed torsional transitions to only $F_{0}$ and $V_{3}^{\prime}\left(=V_{3}\right)$ is attempted. Even though only two frequencies are needed to determine $F_{0}$ and $V_{3}^{\prime}$, it must be required that two or more additional transitions be provided to serve as internal check. The calculated $F_{0}$ will then be referred to the value of $F$ initially computed from the geometry in the ground vibrational state. The difference $\left(F_{0}-F\right)$ can then be related to the change in molecular geometry during the torsional motion. In molecules with relatively heavy frames, it is perhaps a good assumption to consider the change as occurring mainly in the methyl group through some $\mathrm{C}-\mathrm{H}$ elongation or $\mathrm{HCH}$ angle deformation or both. When such calculated changes are reasonably well within expected limits, a successful fit to only $F_{0}$ and $V_{3}^{\prime}$ will mean that $V_{6}^{\prime}$ (or $V_{6}$ itself) is most likely zero. 


\section{WILLIAM G. FATELEY}

In the second step, when the geometry related change $\left(F_{0}-F\right)$ is unreasonably large for a fit to only $F_{0}$ and $V_{3}^{\prime}$ or when no such fit can be successful, the same iteration technique will be applied using $F_{0}, V_{3}^{\prime}$ and $V_{6}^{\prime}$. Whether this operational determination of $F_{0}$ and $V_{6}^{\prime}$ gives the correct contribution of each parameter to the potential is difficult to determine. It is hoped that with enough test cases studied a criterion can be reached as to the extent to which each factor contributes in macromolecular molecules.

\section{SUMMARY}

When put on a firmer foundation, the subject of internal rotation and unbonded forces will undoubtedly have far-reaching implications for understanding the intricate structure of simple molecules which have stable rotamer forms and be of use in understanding macromolecular and biological molecules. At present, the sizable amount of data accumulated on the subject is strictly for the consumption and use of theoretical chemists who are continuously looking for an elegant theory that will explain the origin of the barrier to internal rotation. Our efforts are directed toward understanding conformations in macromolecules.

\section{PART II. REFERENCES}

1 (a) J. P. Lowe, Progr. Phys. Org. Chem. 6, 1 (1968);

(b) Y. Morino and E. Hirota, Annu. Rev. Phys. Chem. 20, 139 (1969);

(c) H. D. Rudolph, Annu. Rev. Phys. Chem. 21, 73 (1970).

2 (a) P. Meakin, D. O. Harris and E. Hirota, J. Chem. Phys. 51, 3775 (1969);

(b) O. L. Stiefvater and E. B. Wilson, J. Chem. Phys. 50, 5385 (1969);

(c) E. Saegebarth and E. B. Wilson, J. Chem. Phys. 46, 3088 (1967);

(d) E. Hirota, J. Molec. Spectrosc. 26, 335 (1968);

(e) E. Hirota, J. Chem. Phys. 37, 283 (1962).

${ }^{3}$ L. Radom, W. J. Hehre and J. A. Pople, to be published.

4 (a) Y. Sasada, M. Takano and T. Satoh, J. Molec. Spectrosc. 38, 33 (1971);

(b) M. Takano, Y. Sasada and T. Satoh, J. Molec. Spectrosc. 26, 157 (1971).

5 (a) Y. S. Li and V. W. Laurie, Symp. Molec. Struct. paper 01 (1969);

(b) T. Masamichi, A. Y. Hirakawa and K. Tamagake, Nippon Kagaku Zasshi, 89, 821 (1968).

${ }^{6}$ G. L. Carlson, W. G. Fateley and F. F. Bentley, Spectrochim. Acta, 28A, 177-179 (1972).

7 Graduate project of A. S. Manocha supported by Carnegie-Mellon University (1971).

${ }^{8}$ R. H. Hunt, R. A. Leacock, C. W. Peters and K. T. Hecht, J. Chem. Phys. 42, 1931 (1965).

9 R. F. Lake and H. W. Thompson, Proc. Roy. Soc. A, 291, 469 (1966).

10 (a) J. P. Lowe and R. G. Parr, J. Chem. Phys. 44, 3001 (1966);

(b) J. P. Lowe, J. Chem. Phys. 45, 3059 (1966).

11 C. S. Ewig and D. O. Harris, J. Chem. Phys. 52, 6268 (1970).

12 D. O. Harris, H. W. Harrington, A. C. Luntz and W. D. Gwinn, J. Chem. Phys. 44, 3467 (1966).

13 W. G. Fateley and F. A. Miller, Spectrochim. Acta, 19, 611 (1963). 